http://jmscr.igmpublication.org/home/ ISSN (e)-2347-176x ISSN (p) 2455-0450

crossref DOI: https://dx.doi.org/10.18535/jmscr/v8i8.42

\author{
Journal Of Medical Science And Clinical Research \\ IGM Publication \\ An official Publication of IGM Publication
}

\title{
Pagets disease Presenting as cardiac failure
}

Authors

\section{Dr Vishal Venugopal ${ }^{1}$, Dr V.R. Mohan Rao ${ }^{2}$, Dr Vinu Boopathy ${ }^{3}$}

${ }^{1}$ Post Graduate, Department of General Medicine, Chettinad Hospital and Research Institute

${ }^{2}$ Professor and Head of the department, Department of General Medicine, Chettinad Hospital and Research Institute

${ }^{3}$ Assistant professor, Department of General Medicine, Chettinad Hospital and Research Institute

\begin{abstract}
Paget's disease was first described by jamespaget in 1877, It is an archetype of a focal bone disorder with accelerated bone turnover. There is an excessive osteoclastic bone resorption which is followed by compensatory increase in osteoblastic activity, resulting in new bone formation, which is structurally disorganised and more prone for deformities and fractures. Estimated prevalence of Pagets disease in India is around $0.066 \%$. We report a case of 72 year old female presenting with low back ache and hard of hearing, on evaluation she was found to have clinical features of pagets disease complicated by sensorineural deafness and bony deformities.
\end{abstract}

\section{Case Report}

A 72 year old female came with complaints of low back ache for past 2 years which was on and off and radiating to legs, it was insidious in onset and progressive in nature. Patient complaints of bilateral hard of hearing for past 1 year insidious in onset and progressive in nature not associated with tinnitus, nausea and vomitting. She was having history of dyspnoea on mild exertion for past 8 months which was insidious in onset and gradually progressive, aggravated by physical and emotional exertion, relieved by rest and it was not associated with chest pain, palpitations, syncopal attacks

On examination patient was concious, afebrile, well oriented to time place and person, Her pulse rate was $98 / \mathrm{min}$ regular, bounding pulse, Blood pressure was $120 / 70 \mathrm{~mm} / \mathrm{hg}$. Patient had bilateral pedal oedema and there was no pallor, icterus, clubbing, cyanosis, lymphadenopathy. There was frontal bossing, enlarged temporal bones, bony deformities involving right $3^{\text {rd }}$ and $4^{\text {th }}$ interphalangeal and metacarpohalangeal joints. Cardiovascular examination revealed an ejection systolic murmur which was heared on all 4 areas with equal intensity and it was non radiating.

Routine laboratory investigations were performed, it revealed normal AST, ALT, GGT, bilirubin and albumin. Alkaline phosphatase was elevated 1717 U/L (reference range: $60-170 \mathrm{U} / \mathrm{l}$ ).calcium and phosphorous was also found to be within normal limits. X ray skull revealed lytic and sclerotic lesions, enlarged cranial cavity, cortical thickening, coarse trabecular markings and cotton wool spots. Pure tone audiometry was performed which revealed bilateral high frequency sensory neural hearing loss. Echocardiogram was done and left ventricular ejection fraction was $50 \%$ with no regional wall motion abnormalities, TAPSE was increased. (33 mm/hg) 
From history, clinical examination and elevated alkaline phophatase, Xray changes patient was diagnose with pagetsdisease, and she was started on zoledronic acid. Following which patient's symptoms started to improve (Bone pain, dyspnoea started to improve).

\begin{tabular}{|l|c|c|}
\hline Investigation & Patients values & Reference range \\
\hline Total protein & $7.0 \mathrm{~g} / \mathrm{dl}$ & $6.4-8.3 \mathrm{~g} / \mathrm{dl}$ \\
\hline Albumin & $4.0 \mathrm{~g} / \mathrm{dl}$ & 3.5 to $5 \mathrm{~g} / \mathrm{dl}$ \\
\hline Globulin & $3.0 \mathrm{~g} / \mathrm{dl}$ & 2.3 to $3.5 \mathrm{~g} / \mathrm{dl}$ \\
\hline Total bilirubin & $0.25 \mathrm{mg} / \mathrm{dl}$ & Upto $1 \mathrm{mg} / \mathrm{dl}$ \\
\hline Direct bilirubin & $0.056 \mathrm{mg} / \mathrm{dl}$ & $0.25 \mathrm{mg} / \mathrm{dl}$ \\
\hline AST & $15 \mathrm{u} / 1$ & 0 to $46 \mathrm{u} / 1$ \\
\hline ALT & $14 \mathrm{u} / 1$ & 0 to $49 \mathrm{u} / 1$ \\
\hline GGT & $13 \mathrm{u} / 1$ & 0 to $38 \mathrm{u} / 1$ \\
\hline $\begin{array}{l}\text { Alkaline } \\
\text { phoshpatase }\end{array}$ & $1713 \mathrm{U} / \mathrm{l}$ & 60 to $170 \mathrm{u} / 1$ \\
\hline calcium & $9.2 \mathrm{mg} / \mathrm{dl}$ & 8.8 to $10.2 \mathrm{mg} / \mathrm{dl}$ \\
\hline Phoshorous & $4.0 \mathrm{mg} / \mathrm{dl}$ & 2.5 to $4.9 \mathrm{mg} / \mathrm{dl}$ \\
\hline
\end{tabular}

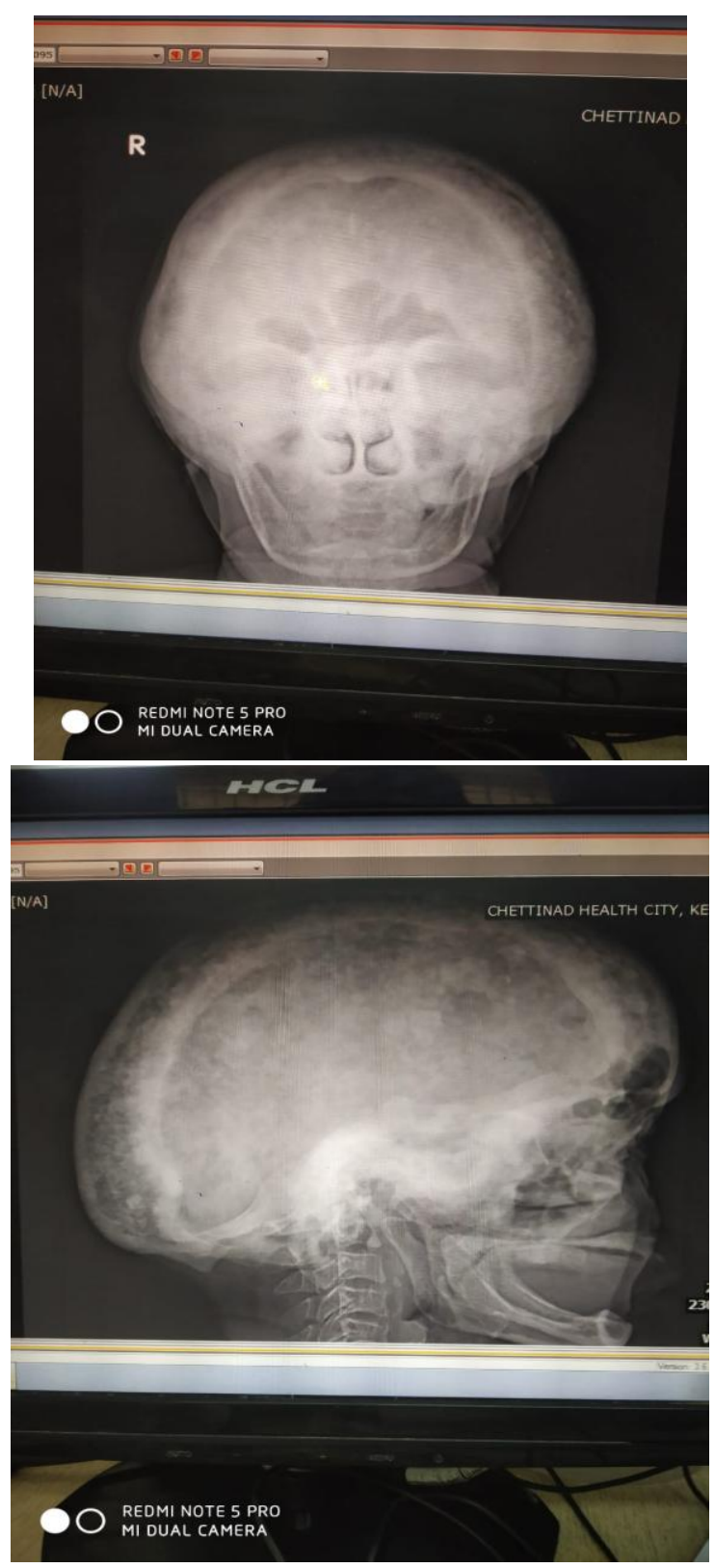

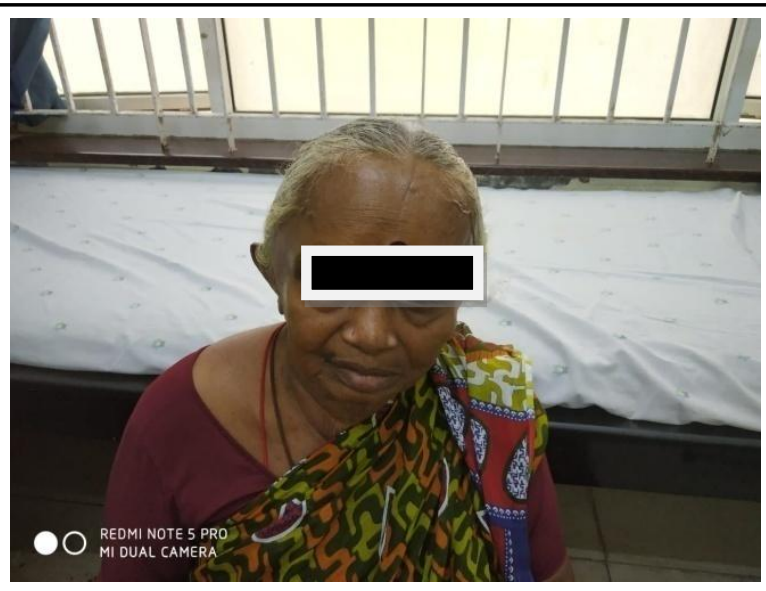

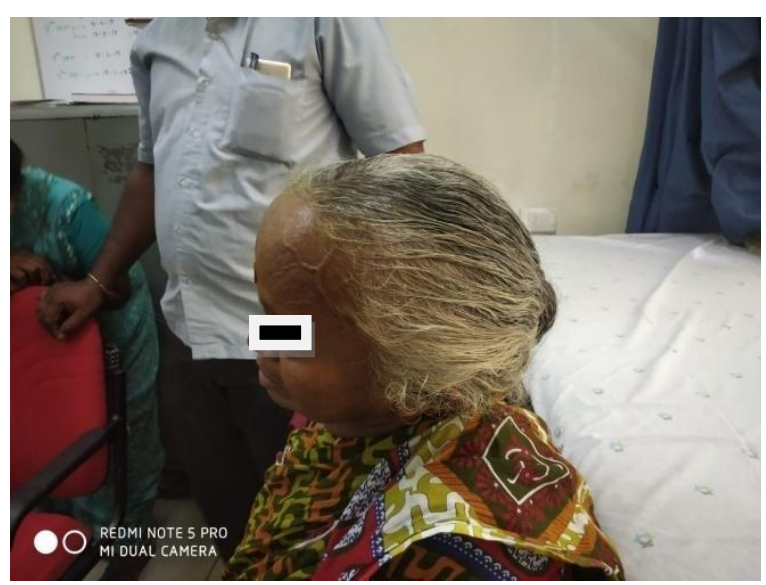

\section{Discussion}

Patients with pagets disease have a wide range of presentation from being asymptomatic to bone lesions, neurological involvement, high output cardiac failure. Pagets commonly involves the axial skeleton with skull, femur, tibia, pelvis and vertebral bodies being the predominant sites to be affected.

Pain is the common presenting symptom (intensity varies depending on the extent of the lesion),it is due to increased bony vascularity, expanding lytic lesions, fractures of weak bones, enlarged vertebrae, spinals tenosis. Bowing of femur or tibia can result in gait abnormalities.

Skull involvement in the form of enlargement of frontal or parietal bones leading to increased head size, this can result in headache, This can result in narrowing of formans and cause neurologic complications including cochlear nerve damage resulting in hearing loss, other cranial nerve palsies(trigeminal neuralgia in rare cases), and softening of the base of the skull which can result in brainstem compression. Our patient had frontal 
bossing, bilateral high frequency sensory neural hearing loss.

Pagets commonly involves facial bones with preponderance to maxilla and mandible, when maxilla increases in size it encroaches the orbit, nasal cavity and antra and produces lion like facies (this can also be seen with lepromatous leprosy).

Fractures are common complication of pagets with preponderance to long bones at areas of active or advancing lytic lesion.

Incidence of sarcoma's are decreasing, may be attributed to early initiation of treatment. Osteosarcomas present as new onset pain in a long standing pagetic bone.

Cardiovascular complications may occur in patients with involvement of extensive portions of the skeleton and a high degree of disease activity (ALP four times above normal). This can be due to excessive demand on the heart from increased vascularity of affected bones, the influence of concomitant arteriosclerosis apparently exceeding the normal for the age concerned, characteristic thoracic spine deformities which compromise cardiorespiratory function. Our patient's ALP was elevated 8 times the normal range and she had high output cardiac failure.

Pagets is usually diagnoses with xray of involved bones which may show both lytic and sclerotic lesions, markers of bone turnover (especially alkaline phosphatase). Bone resorption markers (serum or urine $\mathrm{N}$-telopeptide or C-telopeptide measured in the blood or urine) are also elevated in active Paget's disease and decrease more rapidly in response to therapy than does ALP.

Bisphosphonates are the mainstay of treatment in pagets and maximum response is seen with zoledronic acid, in case of mild disease alendronate and risedronate can be used.

\section{Conclusion}

The prevalence of Pagets disease maybe very low in India, but it still exists in India. Early diagnosis and initiation of bisphosphonates can prevent complications of pagets thus an high index of suspicion is required.

\section{References}

1. C. Franklin Sorneberger, Magnus I smedal, The Mechanism and Incidence of Cardiovascular Changes in Paget's Disease (Osteitis Deformans) A Critical Review of the Literature with Case Studies. doi:doi.org/10.1161/01.CIR.6.5.711

2. Kripa elizabethcherian, Nitinkapoor et al, Paget's disease of bone: An entity still exists in India, Indian journal of endocrinology and metabolism DOI: 10.4103/ijem.IJEM_19_18

3. Y. Udayshankar, satyanranjanmishra et al, Paget disease of bone: A classic case report, Contemporary Clinical dentistry, DOI: 10.4103/0976-237X.114858

4. Epidemiology and pathology of Paget's disease of bone -a review Elena Nebot Valenzuela, DOI 10.1007/s10354-0160496-4

5. Bhadada S, Bhansali A, Unnikrishnan AG, Khadgawat R, Singh SK, Mithal A, et al. Does paget's disease exist in India?: A series of 21 patients. J Assoc Physicians India 2006;54:530- 4. 